\title{
Comparative Study of an Adsorption System Using Zeolite-Water and Silica-Gel-Water Couples: Modeling and Numerical Resolution on Simulink
}

\author{
Mouhamadou Lamine Cisse, Biram Dieng and Amadou Warore \\ Renewable Energy Research Team, Materials and Laser, Department of Physic UFR SATIC, University Alioune DIOP of Bambey \\ Senegal (UADB), Bambey 21400, BP30, Senegal
}

\begin{abstract}
The objective of this work is to model initially, the different components of a single-bed adsorption system with intermittent cold production operating with hot water coming from either biogas (from methanation of animal organic waste), or a flat sensor. Then, in a second step, to the Simulink resolution to determine the evolutions of the desorption temperatures for the two working couples ( Thmax of $180^{\circ} \mathrm{C}$ and $220^{\circ} \mathrm{C}$ ), of the adsorbed fraction $(6 \mathrm{~kg} / \mathrm{s}$ for the zeolite water and $4 \mathrm{~kg} / \mathrm{s}$ for silica gel-water), COP (coefficient of refrigeration performance) of the order of 0.34 for silica gel-water and 0.4 for zeolite-water. These results were compared to those found in the literature for validation. It should be noted that the heat transfer fluid used is water, which has a cold production range between $0{ }^{\circ} \mathrm{C}$ and $10^{\circ} \mathrm{C}$ (cooling applications) and that modeling uses the Dormand-Price OD45 method.
\end{abstract}

Key words: Simulink, zeolite, water, Dormand-Price, temperature, desorption.

\section{Nomenclatures \\ $\rho_{\mathrm{s}} \quad$ density of the sorbent, $\mathrm{kg} / \mathrm{m}^{3}$ \\ Cps Massive heat capacity of the sorbent, $\mathrm{kJ} / \mathrm{kg} \cdot \mathrm{K}$ \\ $\rho g$ density of the adsorbed phase, $\mathrm{kJ} / \mathrm{kg} \cdot \mathrm{K}$ \\ $C$ pa Massive heat capacity of the adsorbed phase \\ $\Delta$ hads Latent heat of adsorption, $\mathrm{kJ}$ \\ $\left(\partial w^{-}\right) / \partial t$ Variation of the adsorbed fraction \\ $\lambda$ e conductivity of the sorbent. $\mathrm{W} / \mathrm{m}^{2}$ \\ $T \mathrm{~s} \quad$ Temperature of the sorbent, $\mathrm{K}$ \\ $h \mathrm{~s}-\mathrm{m} \quad$ Convection coefficient between the sorbent and the \\ outside in $\mathrm{kJ} / \mathrm{kg}$ \\ Tm Ambient temperature \\ of density of the fluid in the sorbent, $\mathrm{kg} / \mathrm{m}^{3}$ \\ Cpf Mass heat capacity of the fluid (adsorbed phase) in \\ the sorbent, $\mathrm{kJ} / \mathrm{kg} \cdot \mathrm{K}$
Tf Temperature of the fluid (adsorbed phase) in the \\ Tf sorbent, $\mathrm{K}$ \\ $\lambda f \quad$ Conductivity of the fluid (adsorbed phase) in the \\ sorbent, $\mathrm{W} / \mathrm{m}^{2}$ \\ $T \mathrm{mc} \quad$ Average temperature in the condenser surface, $\mathrm{K}$ \\ $\mathrm{Mm} \quad$ Mass of the refrigerant in the condenser, $\mathrm{kg}$ \\ $\mathrm{Cpm}$ Massive heat capacity of the refrigerant in the condenser, $\mathrm{kJ} / \mathrm{kg} \cdot \mathrm{K}$}

Corresponding author: Biram Dieng, Ph.D., professor, research field: solar and thermal energy.

\author{
Tc Outside condenser temperature, $\mathrm{K}$ \\ Tco Internal temperature at the condenser, $\mathrm{K}$ \\ $M_{\mathrm{E}} \quad$ Mass of the refrigerant in the evaporator, $\mathrm{kg}$ \\ $C \mathrm{p}_{\mathrm{E}} \quad$ Massive heat capacity of the refrigerant in the \\ evaporator \\ $T_{\mathrm{E}} \quad$ Average temperature in the evaporator, $\mathrm{K}$ \\ $L_{\mathrm{E}} \quad$ Latent heat of evaporation in the evaporator, $\mathrm{kJ} / \mathrm{kg} \cdot \mathrm{K}$ \\ qads $^{b} \quad$ Amount of adsorption heat \\ qdes $^{\mathrm{b}} \quad$ Quantity of desorption heat \\ $\rho$ ch density of the air in the room, $\mathrm{kg} / \mathrm{m}^{3}$ \\ Cpch Massive heat capacity of the air in the room, $\mathrm{kJ} / \mathrm{kg} \cdot \mathrm{K}$ \\ $T \mathrm{ch} \quad$ Average room temperature, $\mathrm{K}$ \\ $h \mathrm{ch} \quad$ convection coefficient between the chamber and the \\ evaporator in $\mathrm{kJ} / \mathrm{kg}$
}

\section{Introduction}

The demand for energy, especially for refrigeration, is considerable [1].

Conventional cooling systems are responsible for the release of large amounts of $\mathrm{CO}_{2}$ into the environment and the use of harmful refrigerants for the greenhouse effect and the potential for ozone depletion. Adsorption refrigeration systems have received a lot of attention because of their cold production using renewable 
energy sources. As a result, intense research over the last 15 years has been interested in solar adsorption refrigeration. Several designs of adsorption refrigeration systems have been studied.

\section{Description of System}

The heat input is done through hot water produced either from the thermal sensor more precisely the vacuum sensor, or from the biogas. The hot water enters the reactor (local between the two cylinders of the reactor) and transmits its heat to the adsorbent (Fig. 1). The latter starts the desorption of the refrigerant contained in it as soon as it reaches the desorption temperature. Then the desorbed fluid being in the form of steam will condense at the condenser with heat rejection. Finally, when it reaches the saturation pressure, the fluid is transmitted to the evaporator. The cooling of the adsorber during the night causes a decrease in the temperature of the adsorbent and the adsorption (production of cold). The control of the system will be by valves.

\section{Mathematical Model}

\subsection{Adsorbent Bed}

Numerous studies have focused on mathematical modeling, particularly for a cylindrical generator, which is the typical configuration, both for the arts and the basic structure of other complex generators $[2,3]$. Because solid adsorption refrigeration is essentially a phenomenon involving heat and mass transfer processes (Fig. 2), the modeling work mainly concerns adsorption performance, heat transfer in the adsorbent bed, and the transfer process coupled mass. Among the different models of adsorption performance, non-equilibrium adsorption models have become increasingly dominant $[4,5]$, while adsorption equilibrium models have received less attention $[6,7]$.

\subsection{Hypotheses}

The mathematical model of the physical problem stated below is based on the following assumptions:

(1) It is considered that the adsorbed phase is liquid.

(2) The adsorbent bed is composed of the same zeolite grains and distributed uniformly [8].

(3) The physical properties of the liquid, the metal and the adsorbent are constant and homogeneous [9].

(4) The thermal resistance between the metal tube and the adsorbent bed is neglected.

(5) The adsorbent bed is homogeneous and isotropic,

(6) The porous particles of zeolites are incompressible.

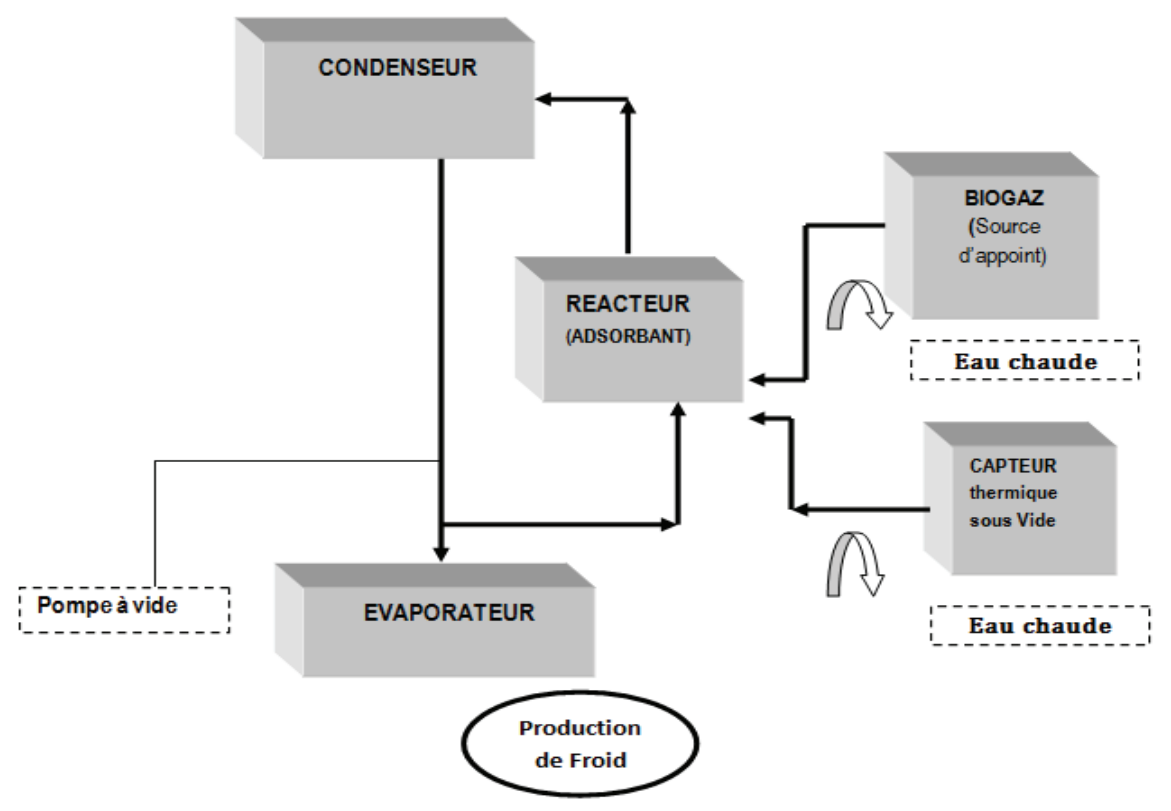

Fig. 1 Study system. 


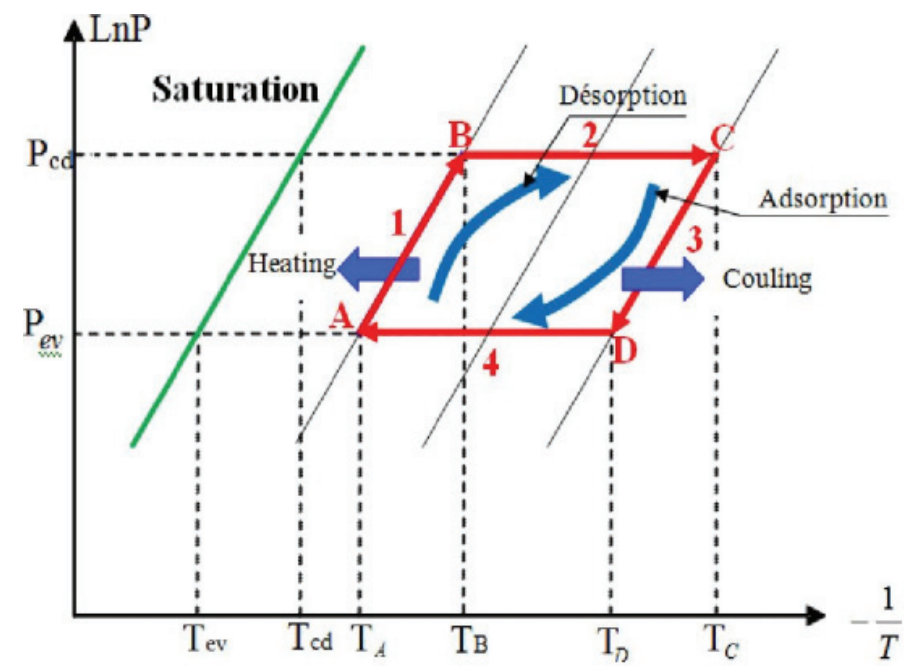

Fig. 2 Adsorption refrigeration cycle.

(7) The air flow is considered one-dimensional.

(8) The walls of the adsorber are supposed adiabatic.

Considering a transfer along the $\mathrm{O}_{Z}$ axis and considering the hypotheses, we obtain:

$$
\begin{aligned}
\left(\rho_{s} C_{p s}+\rho_{g} \mathrm{w} C_{p a}\right) & \frac{\delta T_{s}}{\delta \mathrm{t}} \\
= & \frac{\partial}{\partial \mathrm{z}}\left(\lambda \mathrm{n} * \frac{\partial T_{s}}{\partial \mathrm{z}}\right) \\
& -\frac{2 * h_{s}-\mathrm{m}}{\mathrm{D} 1}\left(T_{s}-T_{m}\right) \\
& +\rho_{s} \Delta H_{a d s} \frac{\partial \overline{\mathrm{w}}}{\partial \mathrm{t}}
\end{aligned}
$$

\subsubsection{Condenser}

Energy conservation equation for the condenser:

$$
\begin{aligned}
\left(M_{m} C_{p m}\right) \frac{\delta T_{m}^{c}}{\delta \mathrm{t}}= & -h_{m} A_{m_{\mathrm{ex}}}\left(T_{m}^{c}-T_{c}\right) \\
& -h_{m} A_{m_{\mathrm{in}}}\left(T_{m-}^{c} T_{c o}\right) \\
& +\frac{\lambda_{m}}{V_{m}} \frac{\partial}{\partial \mathrm{z}}\left(\frac{\partial T_{m}^{c}}{\partial z^{2}}\right)
\end{aligned}
$$

\subsubsection{Evaporator}

Energy conservation equation for the evaporator:

$$
\begin{aligned}
\left(M_{E} C_{p E}\right) \frac{\delta T_{E}}{\delta \mathrm{t}}= & -L_{E} * M_{s} \frac{\partial q_{a d s}^{b}}{\partial \mathrm{t}} \\
& +\left(h_{f} * M_{s} \frac{\partial q_{d e s}^{b}}{\partial \mathrm{t}}\right)
\end{aligned}
$$

\subsubsection{Cold room}

Conservation equation of the room:

$$
\begin{aligned}
\left(\rho_{c h} C_{c h}\right) \frac{\delta T_{c h}}{\delta \mathrm{t}}= & -U_{c h} \rho_{c h} C_{c h} \frac{\delta \mathrm{T}_{c h}}{\delta \mathrm{z}} \\
& -\frac{2 * h c h}{d e}\left(T_{c h}-T_{E}\right) \\
& +\lambda_{f} \frac{\partial}{\partial \mathrm{z}}\left(\frac{\partial T_{c h}}{\partial z}\right)
\end{aligned}
$$

\subsubsection{Calculation of the COP}

$$
\begin{aligned}
& Q e v=M s * L(T e) * \int_{T s 2}^{T a} \frac{d w(t)}{d t} * d t-M s \\
& * C p f \\
& *\left[\int_{T s 2}^{T a} \frac{d w(t)}{d t} * d t\right] \int_{T e v}^{T c o n d} d t \\
& \text { Qdes }=M s * L(T e) * \int_{T s 1}^{T g} M s *(C p s+\operatorname{mads}) \\
& * C p f * d t \\
&+\left[\int_{T s 2}^{T g} M s * Q s t * \frac{d w(t)}{d t}\right. \\
&* d t] \int_{T e v}^{T c o n d} d t \\
& C O P=\frac{Q_{e v}}{Q_{d e s}}
\end{aligned}
$$

\subsection{Numerical Solution}

The numerical method used on Matlab is that of Dormand-Price. This method is nothing more than the EULER 45 order. The simulation was made from the 

Modeling and Numerical Resolution on Simulink

blocks (Figs. 3-8) of the mathematical models. The given in Table 1 and the data of blocks in Table 2.

primary data used in the numerical calculations are

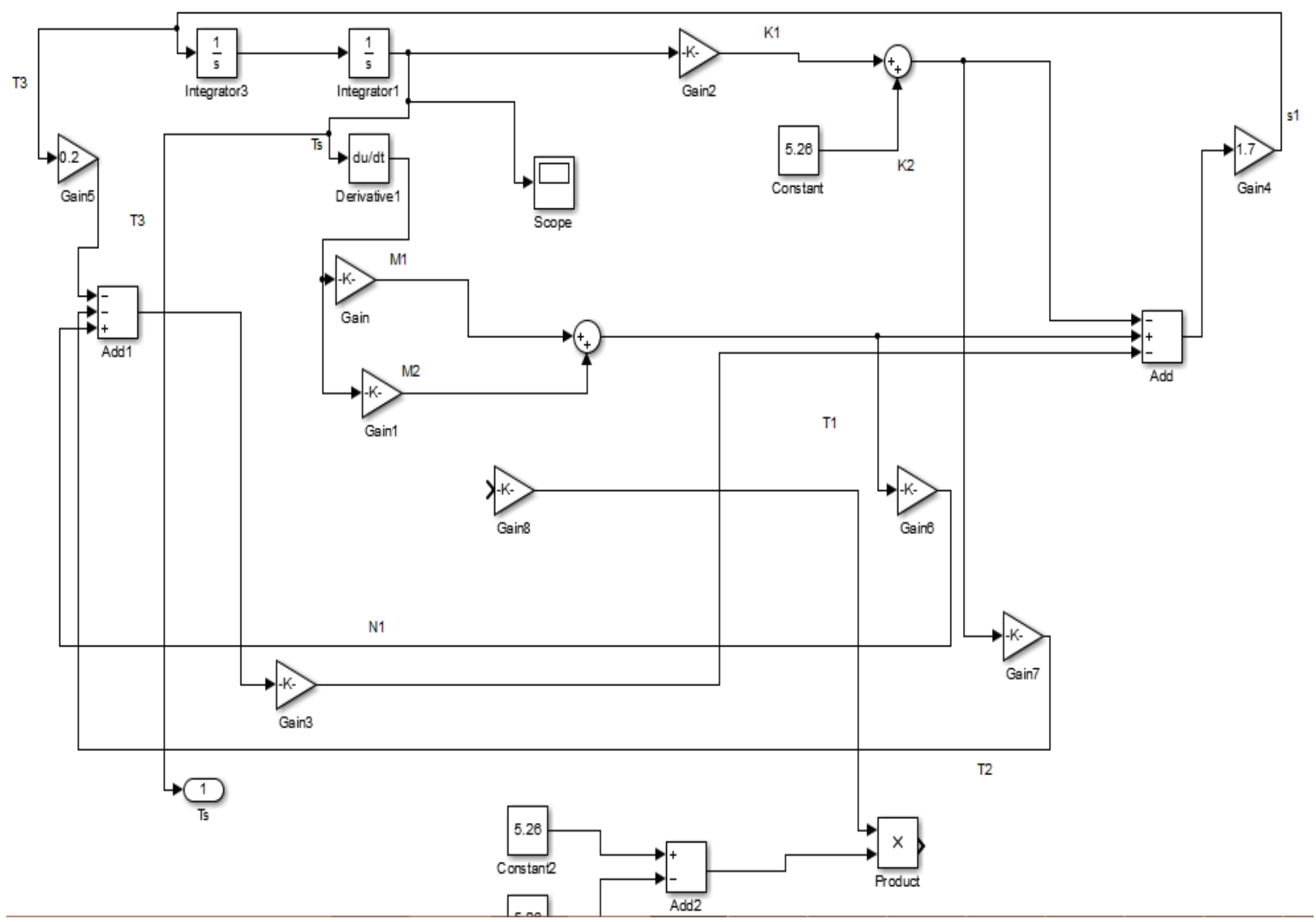

Fig. 3 Block of the adsorbent bed.

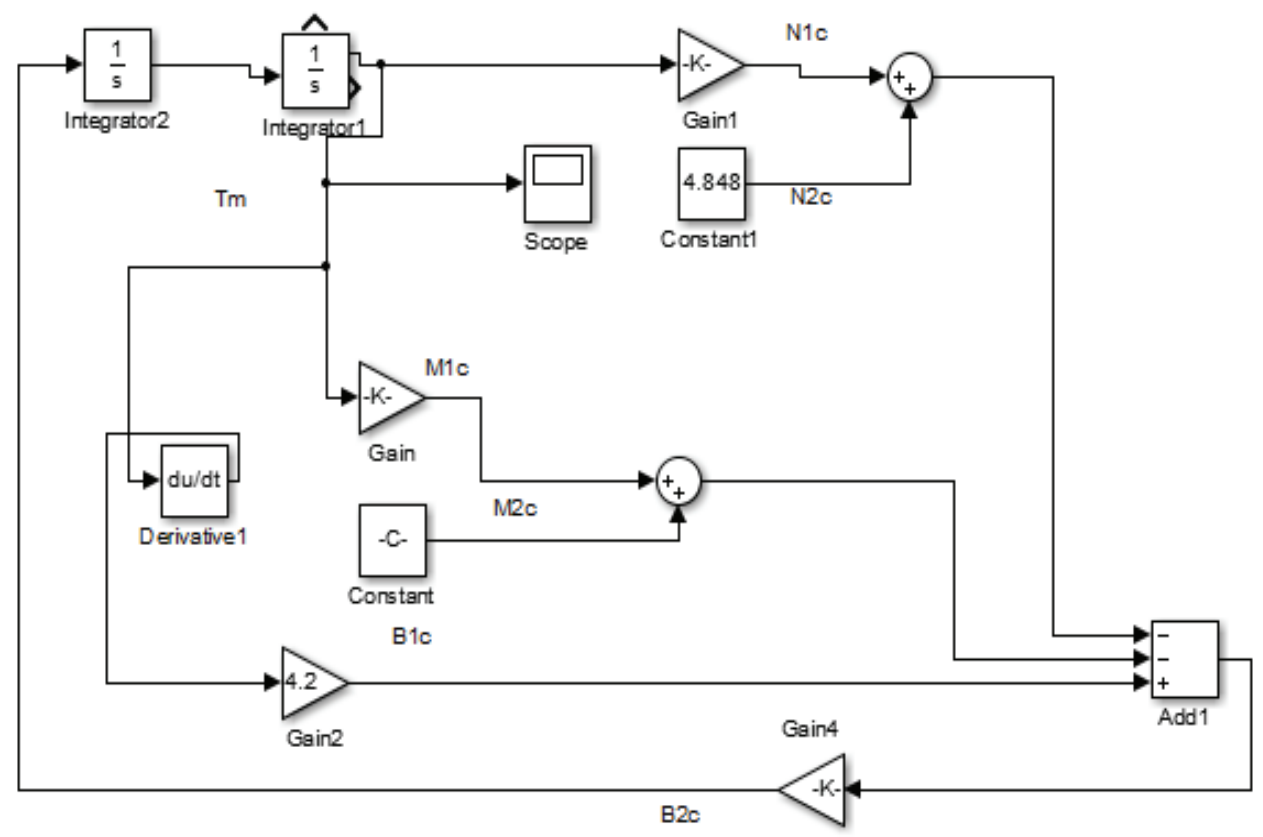

Fig. 4 Condenser block. 
Comparative Study of an Adsorption System Using Zeolite-Water and Silica-Gel-Water Couples: Modeling and Numerical Resolution on Simulink

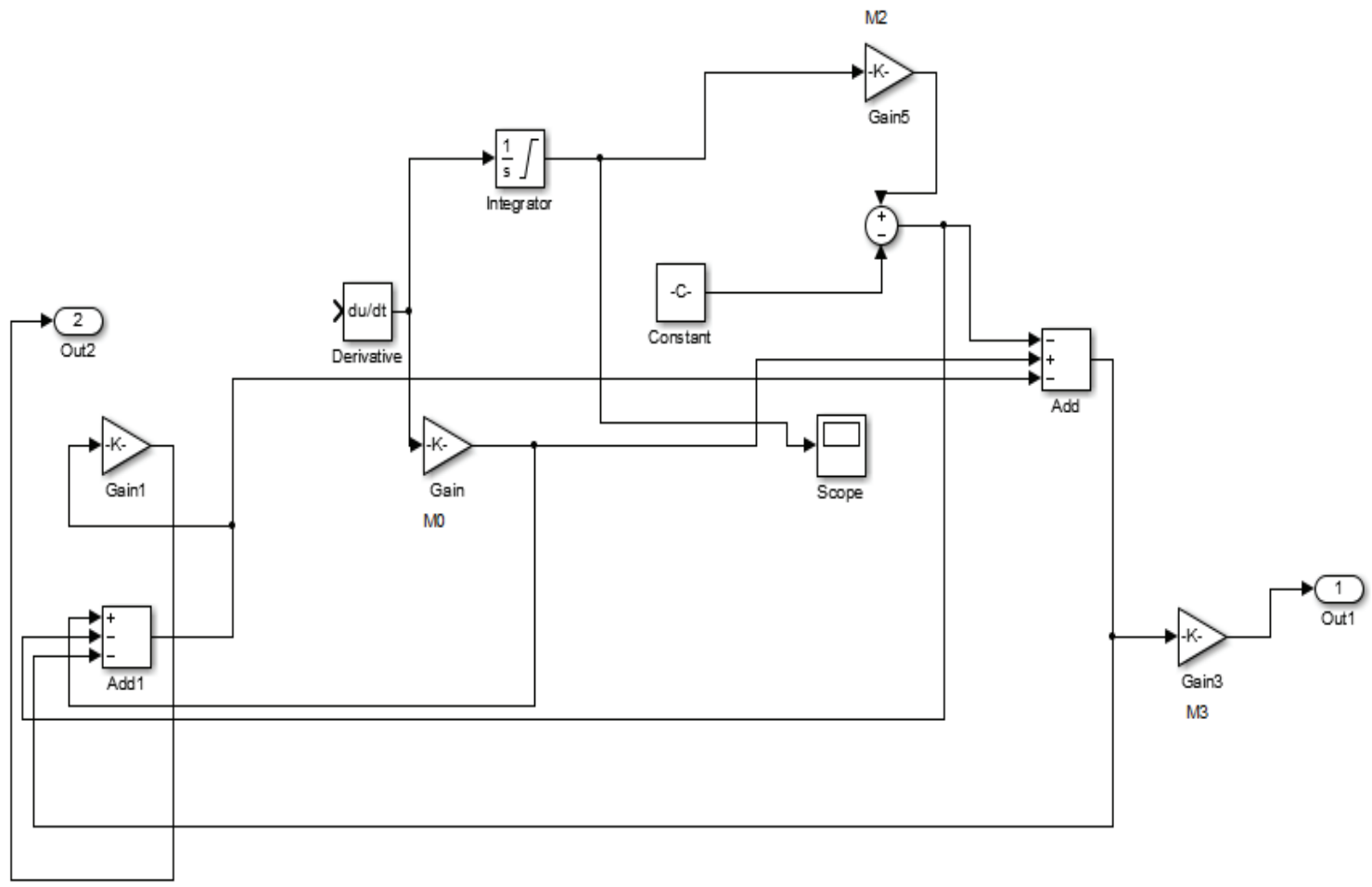

Fig. 5 Evaporator block.

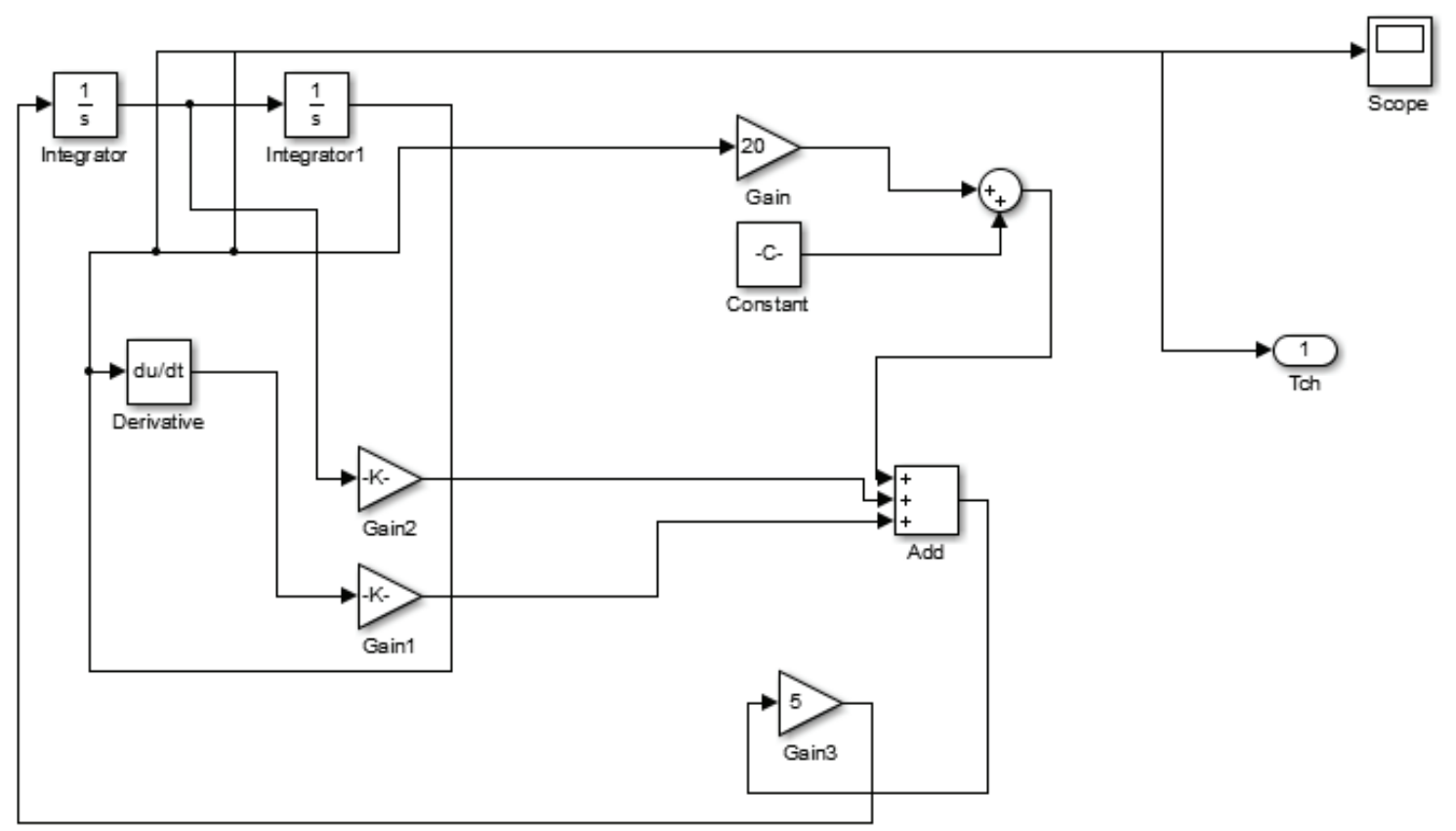

Fig. 6 Room block. 

Modeling and Numerical Resolution on Simulink

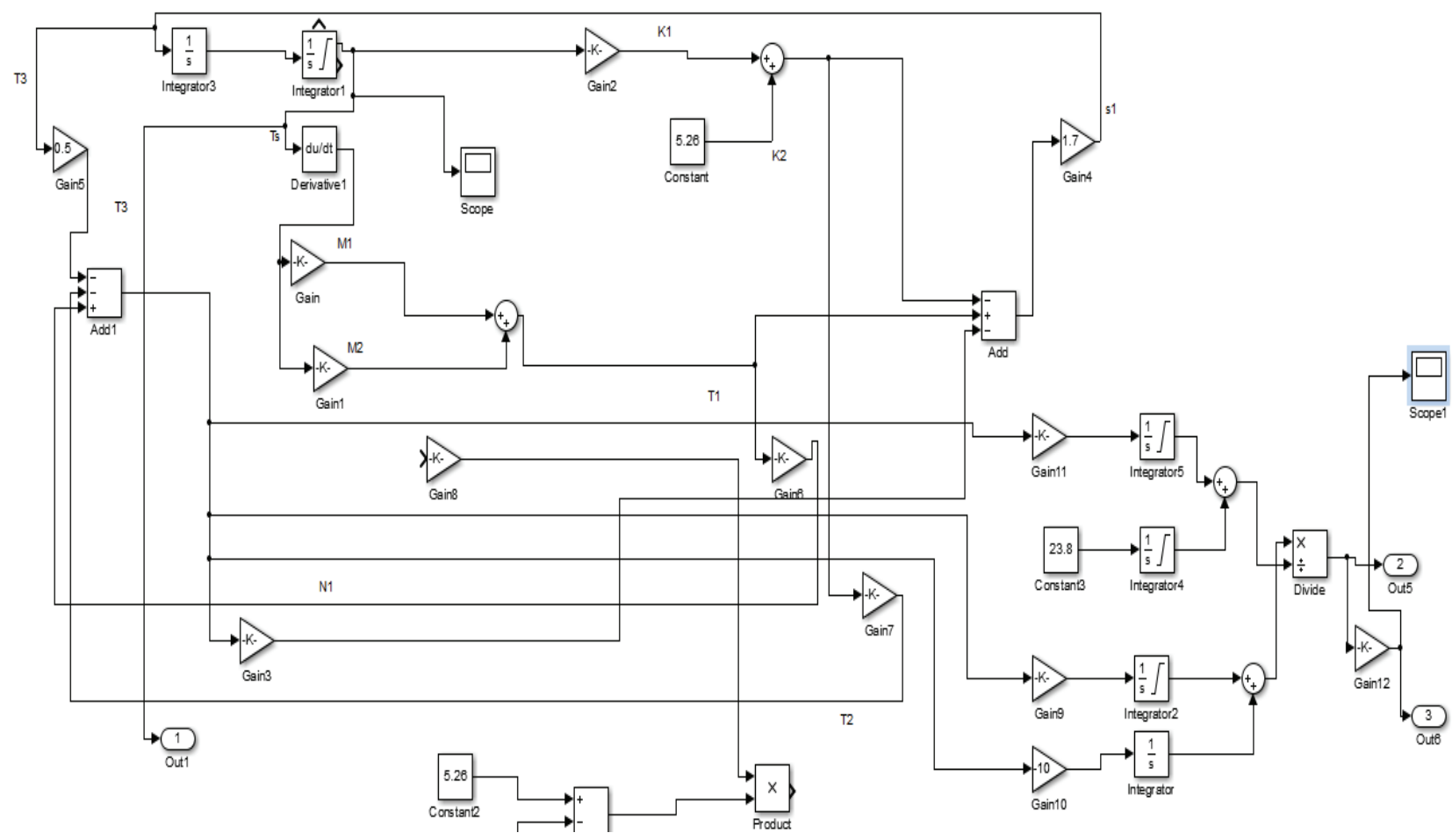

Fig. 7 Block for the calculation of the COP.

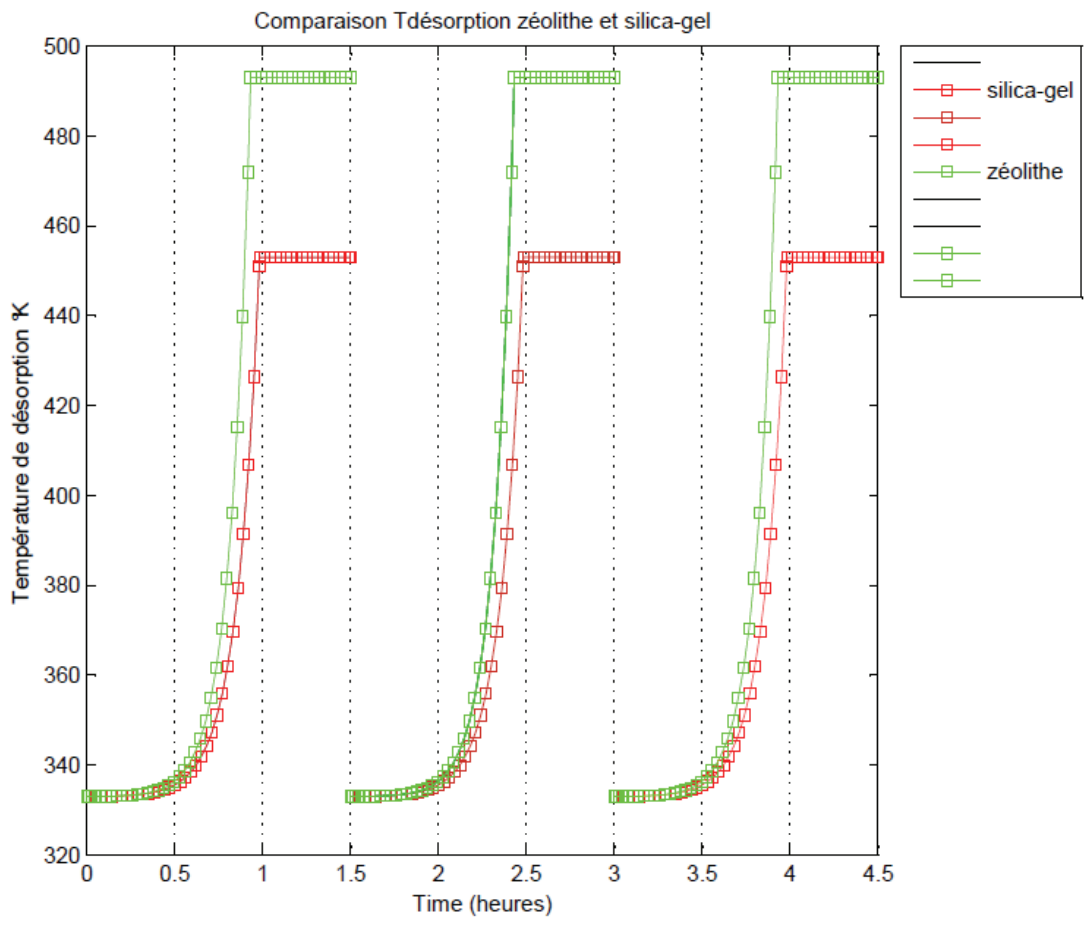

Fig. 8 Comparison variation of the temperature desorption as a function of time. 
Table 1 Input parameters of model.

\begin{tabular}{lll}
\hline Symbol & Value & $\mathrm{Unit}$ \\
\hline Ros & 896 & $\mathrm{~kg} / \mathrm{m}^{3}$ \\
Cps & 1.04 & $\mathrm{~kJ} / \mathrm{kg} \cdot \mathrm{K}$ \\
Rog & 500 & $\mathrm{~kg} / \mathrm{m}^{3}$ \\
w & 0.3 & $\mathrm{~kg} / \mathrm{kg}$ \\
Cpa & 0.462 & $\mathrm{~kJ} / \mathrm{kg} \cdot \mathrm{K}$ \\
hs-m & 15 & $\mathrm{~W} / \mathrm{m}^{2} \cdot \mathrm{K}$ \\
$\Delta$ Hads & 1,200 & $\mathrm{~kJ}$ \\
lamda & 0.56 & $\mathrm{~W} / \mathrm{m} \cdot \mathrm{K}$ \\
D1 & $3.45 \times 10^{5}$ & - \\
\hline
\end{tabular}

Table 2 Block data.

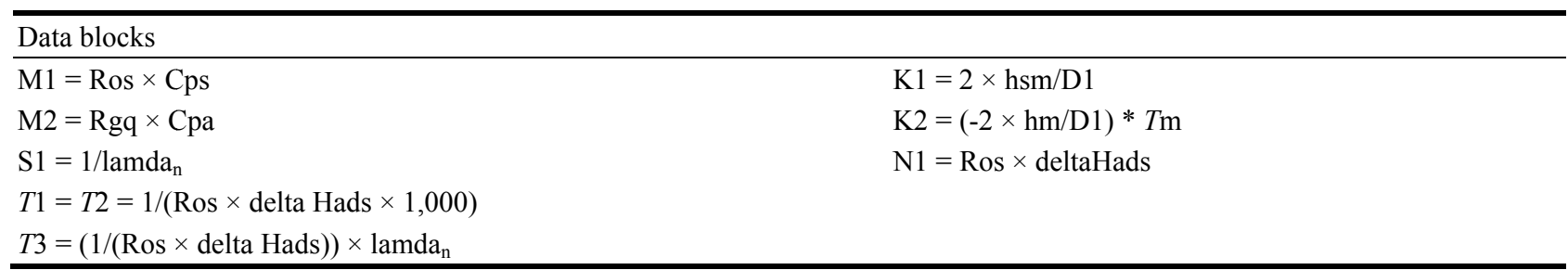

\section{Resultat and Discussion}

Fig. 8 shows an increasing evolution of the desorption temperature until reaching $T$ hmax $=220^{\circ} \mathrm{C}$, $490 \mathrm{~K}$ for the zeolite and $\mathrm{Thmax}=180^{\circ} \mathrm{C}$ for the silica gel. By comparing the two curves, it can be seen that the desorption temperature is much higher for the zeolite. Thmax $=180^{\circ} \mathrm{C}$ for silica gel, desorption time $=5,400 \mathrm{~s}$.

The same variation is noted in Fig. 9.

Fig. 10 shows the variation of the temperature along the $\mathrm{O}_{\mathrm{z}}$ axis of the sorbent. It gives a max value of 14
$\mathrm{K} / \mathrm{cm}$ for the zeolite and $9.5 \mathrm{~K} / \mathrm{cm}$ for the silica gel. It implies that the temperature of the zeolite changes from $220{ }^{\circ} \mathrm{C}$ to $203{ }^{\circ} \mathrm{C}$ along the $\mathrm{O}_{\mathrm{z}}$ axis and the silica gel from $180^{\circ} \mathrm{C}$ to $170.5^{\circ} \mathrm{C}$.

This variation is greater for zeolite, which also has better conductivity compared to silica gel.

In Fig. 11, we see a growth of the condensation temperature which reaches the maximum value of $35^{\circ} \mathrm{C}$.

Regarding the variation of the adsorbed fraction, it is increasing over time (Fig. 12). And it reaches up to 6 $\mathrm{kg} / \mathrm{s}$ for zeolite and around $4 \mathrm{~kg} / \mathrm{s}$ for silica gel.
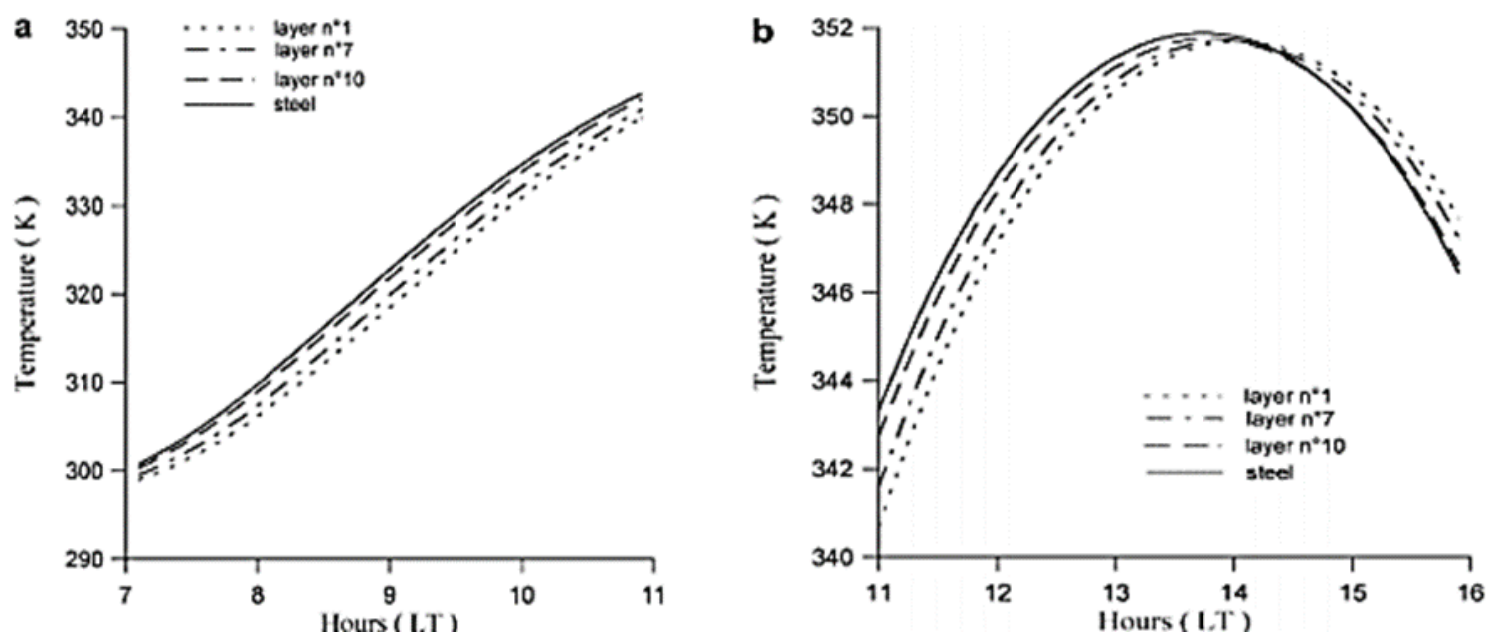

Fig. 9 Temperature distribution in a tubular solar reactor, during the heating phases, according to Aroudam, El. H. [9]. 

Modeling and Numerical Resolution on Simulink

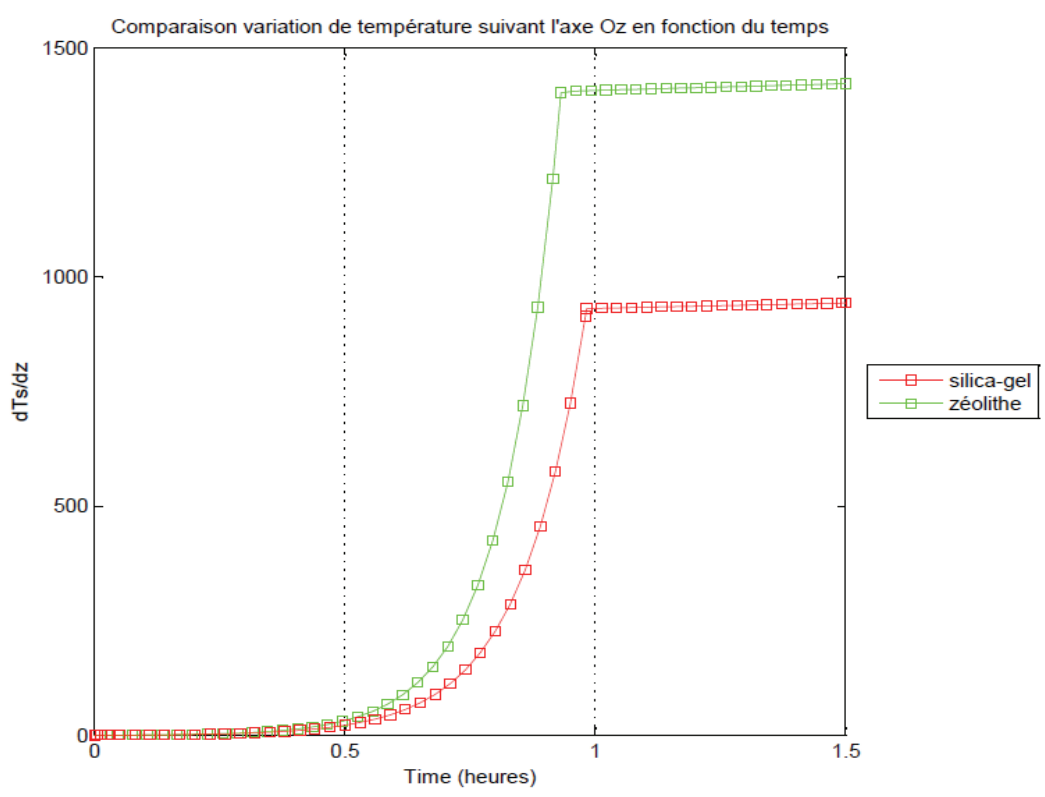

Fig. 10 Comparison variation of desorption temperature along the $\mathrm{O}_{\mathrm{z}}$ axis as a function of time.

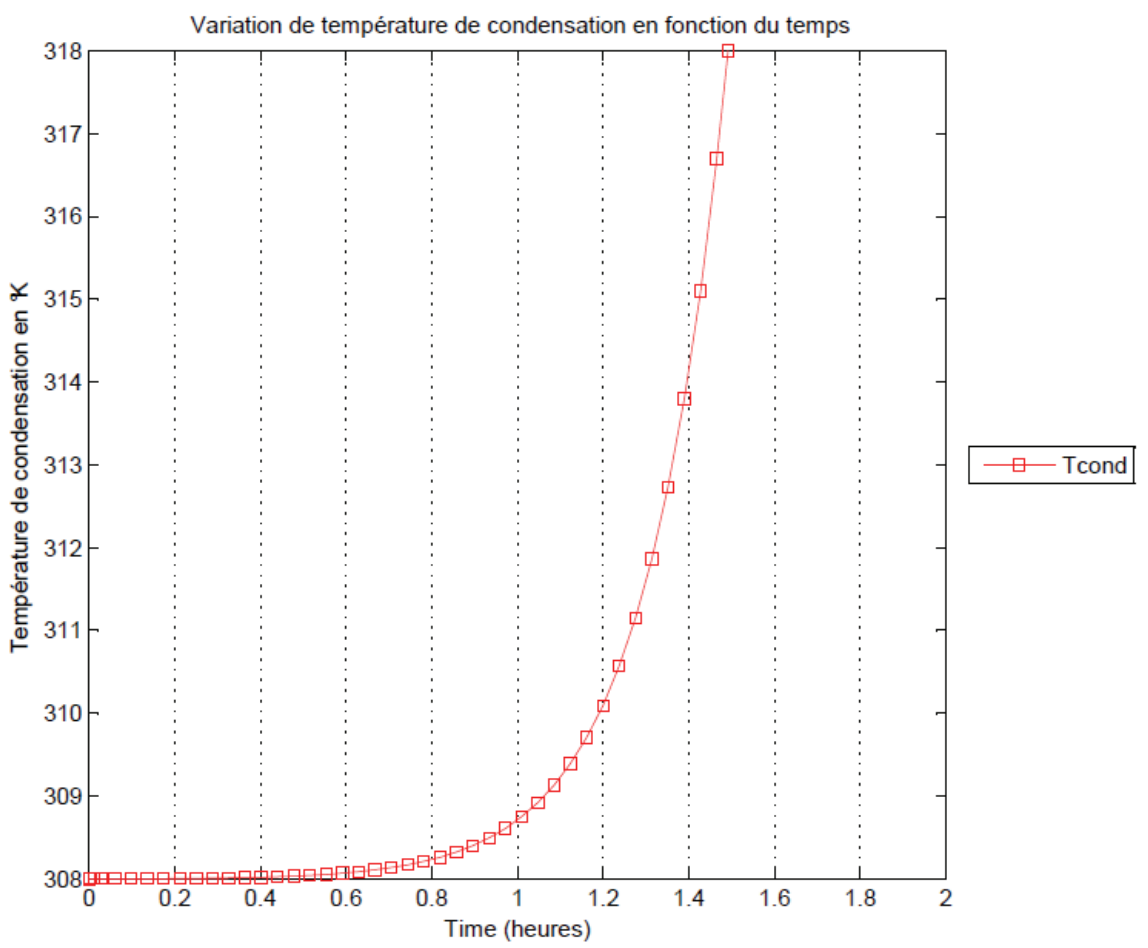

Fig. 11 Variation of condensation temperature as a function of time. $T \mathrm{c}=35^{\circ} \mathrm{C}, 308 \mathrm{~K}$. 
Comparative Study of an Adsorption System Using Zeolite-Water and Silica-Gel-Water Couples: Modeling and Numerical Resolution on Simulink

Case of sorbent silica gel and zeolite

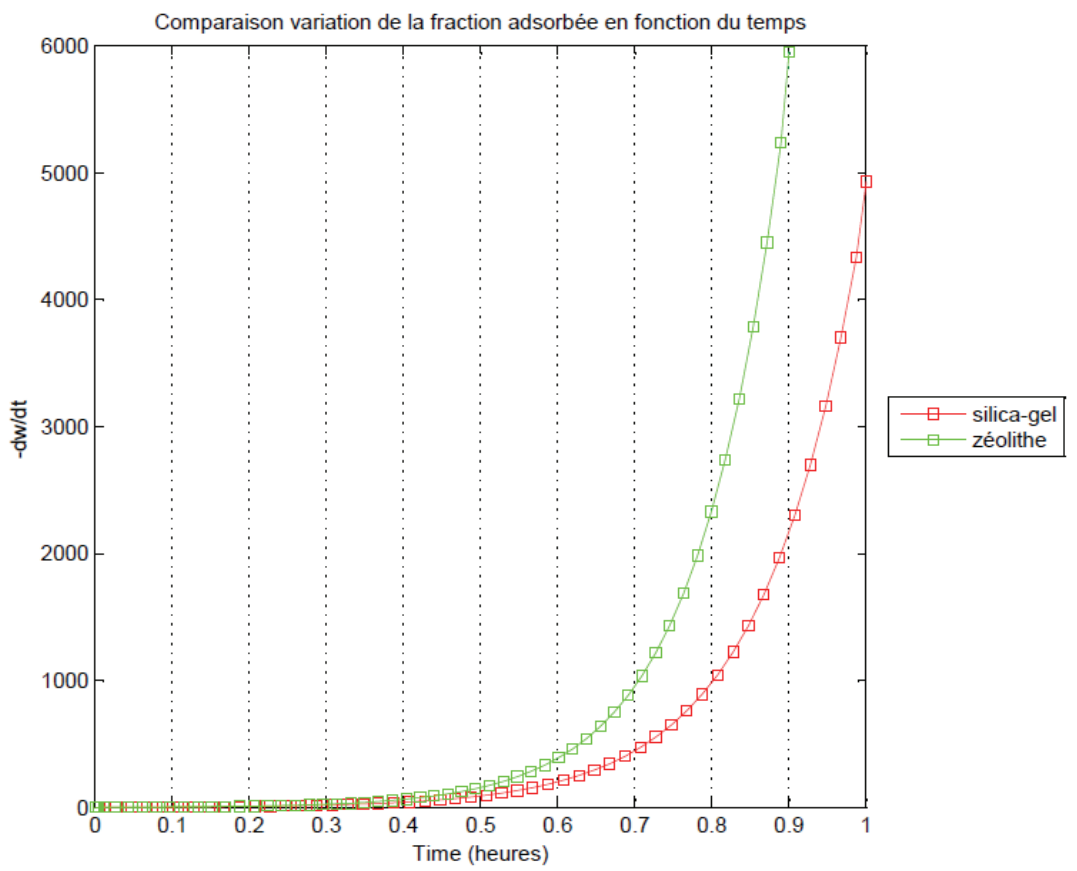

Fig. 12 Comparison variation of the adsorbed fraction as a function of time.

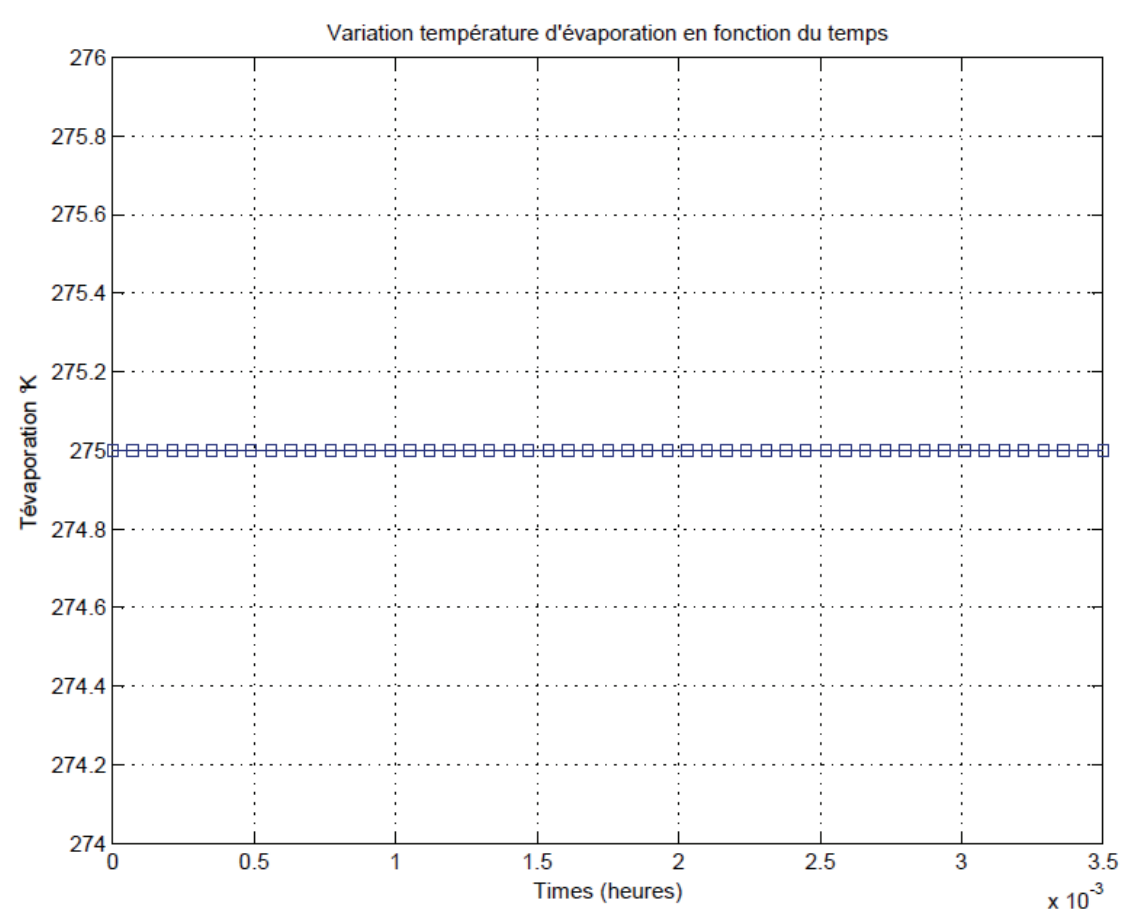

Fig. 13 Variation of the evaporation temperature as a function of time Tévap $=275 \mathrm{~K}$. 

Modeling and Numerical Resolution on Simulink

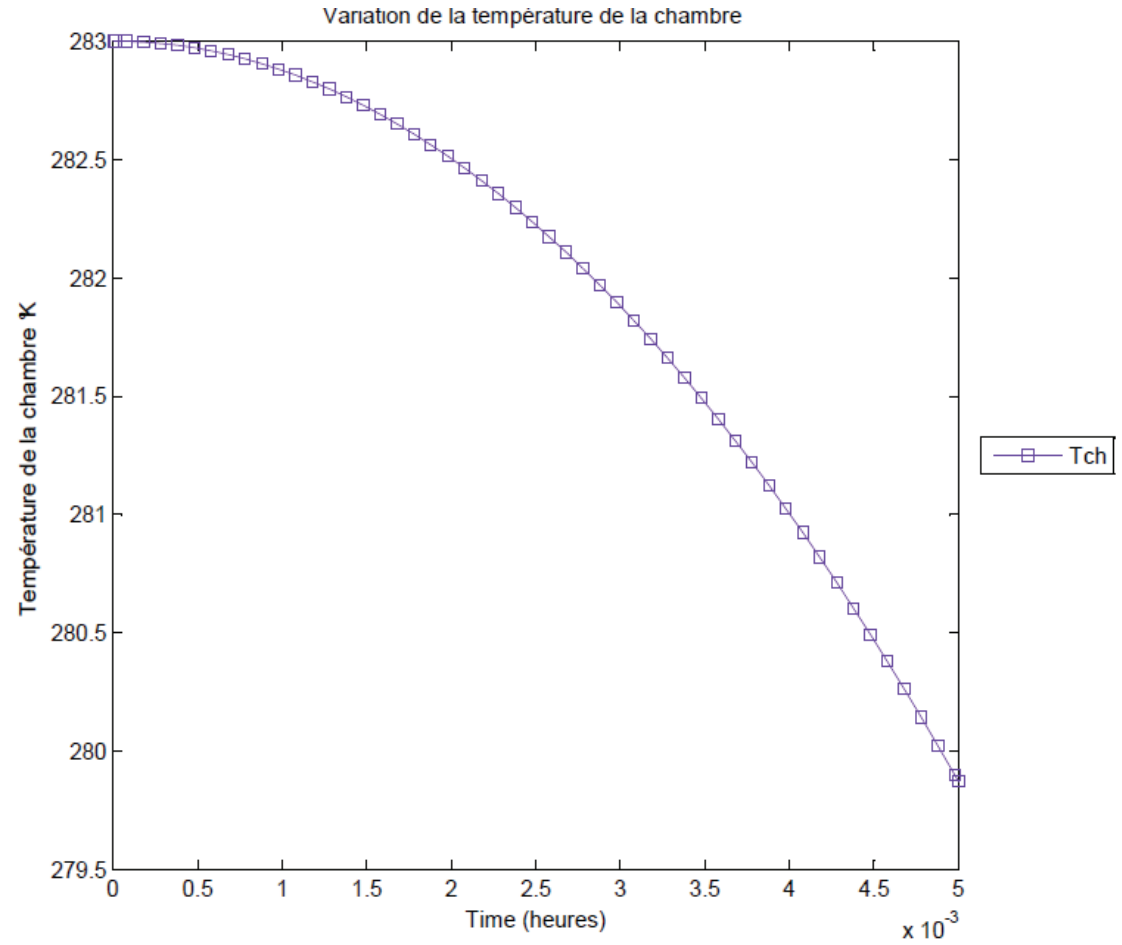

Fig. 14 Variation of room temperature as a function of time.

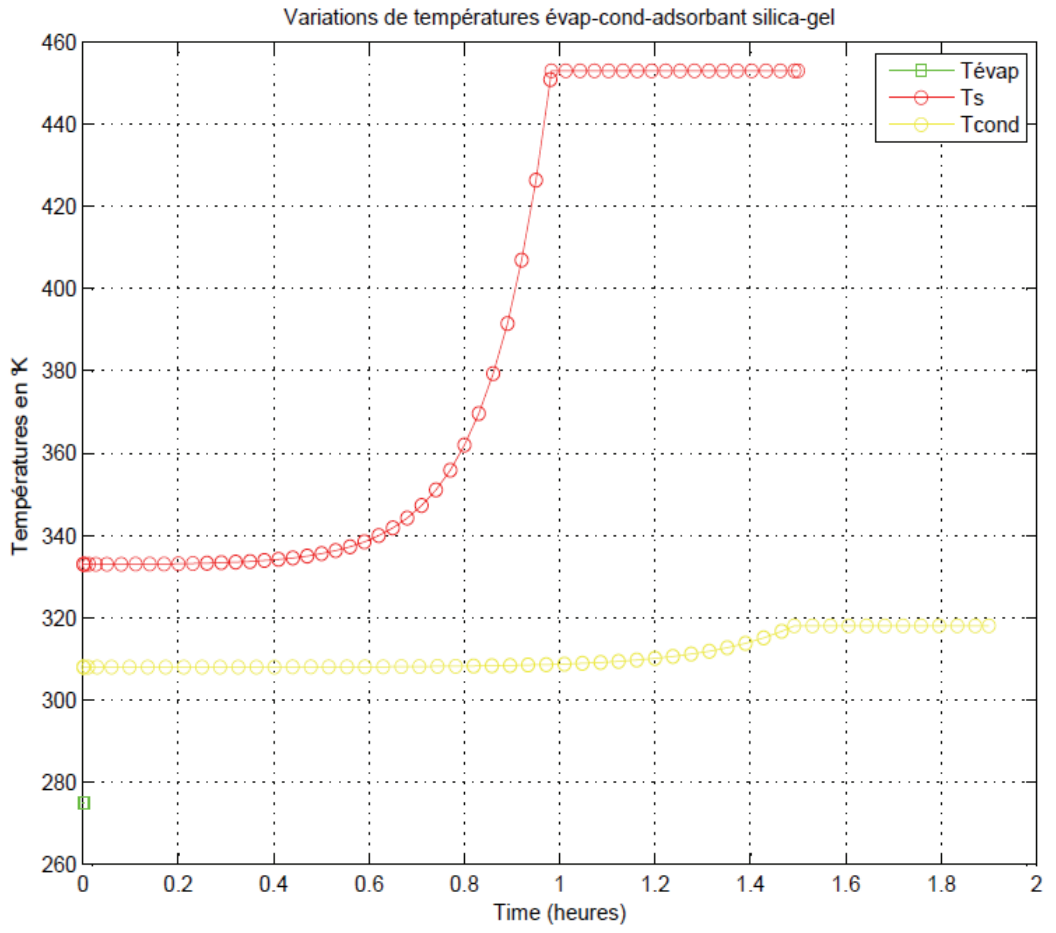

Fig. 15 Variation of the evaporator, condenser and adsorbent temperatures as a function of time. 


\section{Comparative Study of an Adsorption System Using Zeolite-Water and Silica-Gel-Water Couples: Modeling and Numerical Resolution on Simulink}

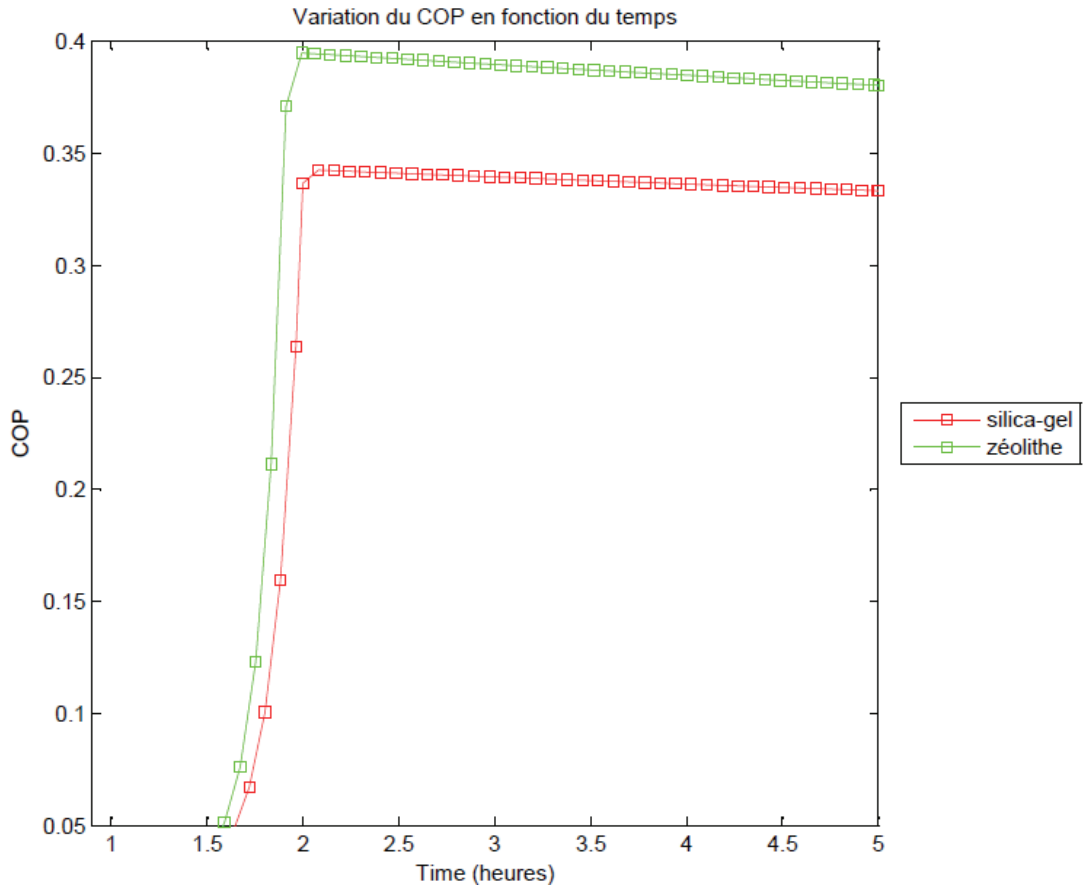

Fig. 16 Variation of the silica-gel and zeolite COP as a function of time.

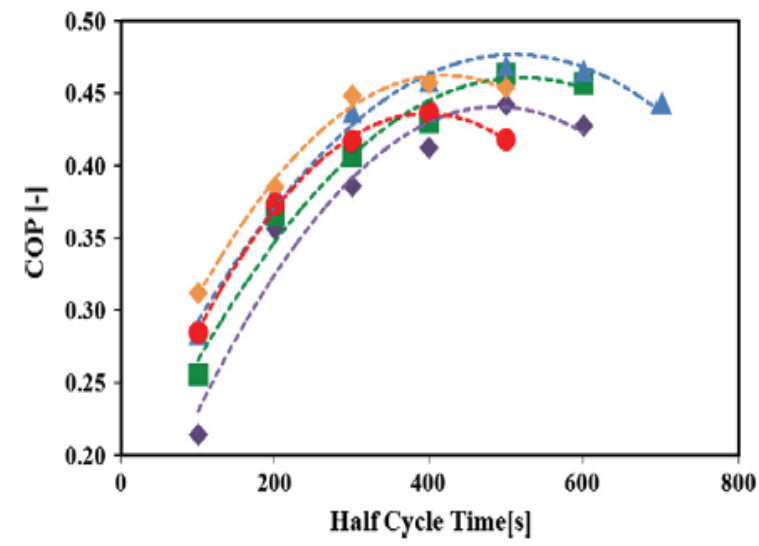

Fig. 17 Variation of the COP as a function of time [10].

From Fig. 13, the evaporator temperature is constant over time. It is equal to $2^{\circ} \mathrm{C}$.

His value is above $0^{\circ} \mathrm{C}$ and allows cold production at positive temperatures.

For the temperature of the chamber (Fig. 14), it goes from $10{ }^{\circ} \mathrm{C}$ initial value to a temperature of $6.9{ }^{\circ} \mathrm{C}$. This suggests a cold production below $8{ }^{\circ} \mathrm{C}$ (cooling applications).

The summary of the different temperatures is prescribed in Fig. 15.

Fig. 16 shows an increase in $\mathrm{COP}$ over time. It reaches a maximum value of 0.34 and 0.4 . This number is close to the value 0.42 given in the literature (Fig. 17). This COP is low for adsorption systems compared to absorption systems.

\section{Conclusion}

This modeling and simulation work made it possible to determine the evolution of temperatures in the case of a cylindrical reactor adsorption system. After inserting the input parameters of our model, these results were subsequently compared with those of other studies to measure validity.

\section{References}

[1] Afonso, C. F. A. 2006. "Recent Advances in Building Air Conditioning Systems." Applied Thermal Engineering 26: 1961-71.

[2] Zhao, H. Z., Zhang, M., Liu, Z. Y., Liu, Y. L., and Ma, X. D. 2008. "Mechanical and Experimental Study on Freeze Proof Solar Powered Adsorption Cooling Tube Using Active Carbon/Methanol Working Pair." Energy Convers Manage 49: 2434-8.

[3] Mers, A. A., Azzabakh, A., Mimet, A., and Kalkha, H. E. 2006. "Optimal Design Study of Cylindrical Finned Reactor for Solar Adsorption Cooling Machine Working with Activated Carbon-Ammonia Pair." Appl Therm Eng 26: 1866-75. 

Modeling and Numerical Resolution on Simulink

[4] Leong, K. C., and Liu, Y. 2004. "Numerical Modeling of Combined Heat and Mass Transfer in the Adsorbent Bed of a Zeolite/Water Cooling System." Appl Therm Eng 24: 2359-74.

[5] Yang, P. Z. 2009. "Heat and Mass Transfer in Adsorbent Bed with Consideration of Non-equilibrium Adsorption." Appl Therm Eng 29: 3198-203.

[6] Zhang, X. J., Liu, H. X., Wang, R. Z., and Shi, F. 2002. "Numerical Simulation of Heat Transfer in Regenerator of Solid Adsorption Refrigeration System." Renew Energy 26: 599-610.

[7] Hu, J., and Exell, R. H. B. 1994. "Simulation and Sensitivity Analysis of an Intermittent Solar Powered
Charcoal/Methanol Refrigerator." Renew Energy 4: 133-49.

[8] Sun, L. M., Amar, N. B., and Meunier, F. 1995. "Numerical Study on Coupled Heat and Mass Transfers in an Absorber with External Fluid Heating." Heat Recovery Systems and Chp 15 (1): 19-29.

[9] Aroudam, El. H. 2002. "Numerical Modelling of Heat and Mass Transfer in Adsorption Solar Reactor of Ammonia on Active Carbon." Heat and Mass Transfer 39 (1): 47-55.

[10] Myat, A., Choon, N. K., Thu, K., and Kim, Y. D. 2013. "Experimental Investigation on the Optimal Performance of Zeolite-Water Adsorption Chiller." Applied Energy 102: 582-90. 